\title{
Editorial
}

\section{Wildson Luiz Pereira dos Santos}

Eduardo Fleury Mortimer efmortimer@gmail.com Universidade Federal de Minas Gerais (UFMG), Belo Horizonte, Minas Gerais, Brasil
É uma tarefa muito difícil escrever esse texto, que me foi encomendado pela ACTIO: Docência em Ciências. Wildson era uma pessoa muito especial, um grande educador químico, um homem de qualidades, dedicado a sua família, a sua vida profissional e ao seu trabalho voluntário junto a crianças carentes. Mas era também um grande amigo e a dor de sua perda é irreparável.

Me lembro perfeitamente do momento em que Wildson conversou comigo, em 1997, sobre a possibilidade de orientá-lo no seu doutoramento. Viajávamos de Porto Alegre para ljuí, com a finalidade de participarmos do XVII Encontro de Debates sobre Ensino de Química, os pioneiros e renomados EDEQs. Eu iniciara a orientação de doutorandos no Programa de Pós-graduação em Educação da UFMG em 1995, portanto apenas 2 anos e alguns meses antes de receber o pedido do Wildson. Conversamos longamente sobre o projeto que ele tinha em mente naquele momento, ligado a entender como os professores que adotavam o PEQUIS - que nos legaria preciosos livros didáticos para o ensino médio de química - transformavam a sua concepção de ensino de química e de educação. Ele continuaria nas mesmas linhas com a quais já vinha trabalhando: educação para a cidadania, educação CTS e questões sócio-científicas, algo a que já havia dedicado seu mestrado, cursado na Faculdade de Educação da UNICAMP sob a competente orientação de Roseli Schnetzler. Neste XVII EDEQ, em ljuí, seria lançado, pela Editora UNIJUí, o livro Educação em Química: Compromisso com a cidadania, uma coautoria de Wildson e Roseli, que coroava o seu mestrado. Estava claro que eu aceitaria Wildson. Ela expressava confiança em seu projeto, entusiasmo com a tarefa que apenas se descortinava perante seus olhos atentos, abnegação para enfrentar as dificuldades que porventura se fizessem presentes em seu caminho. Já vai longe o tempo em que começamos a tecer os fios de uma grande amizade.

Em 1998, Wildson começava em Belo Horizonte seus estudos de doutorado. Neste ano, apenas cursou as disciplinas, que tomariam grande parte do seu tempo, e se dedicou a melhorar o projeto, que deveria ser submetido até o final do ano. Mas, aos poucos, Wildson começava a revelar as qualidades que marcariam nosso convívio, a nossa amizade e a sua atuação profissional. Em nossas conversas, eu havia Ihe revelado a possibilidade de ele cursar um ano de seu doutorado na Inglaterra, com o também grande amigo, o saudoso Phil Scott. Ele se entusiasmara com a perspectiva e começara a estudar inglês. Sempre muito disciplinado, ao rever a bibliografia para o seu projeto, já no fim de 1998, me falara da vontade de escrever um artigo em que abordássemos as várias visões CTS disponíveis na literatura. Estava nascendo, naquele momento, a primeira das nossas colaborações, "Uma Análise de Pressupostos Teóricos da Abordagem C-T-S (Ciência-Tecnologia-Sociedade) no Contexto da Educação Brasileira", artigo que seria publicado em 2000, no segundo volume de "Ensaio: Pesquisa em Educação em Ciências". Tenho um grande orgulho de ter ajudado Wildson a escrever esse e outros artigos. Do processo nem sempre fácil de idas e vindas, o primeiro texto dessa nossa colaboração selou nossa amizade. Nascia um produto de qualidade que continua a ter um impacto na educação em ciências, haja visto o número de citações no Google Scholar, por exemplo. 
Como o tempo passa rápido em relação às boas experiências que vivemos. Já estávamos em 2000 e Wildson partiria com toda a família para Leeds, no norte da Inglaterra, trilhando os mesmos caminhos que um dia eu havia feito. E como é duro ir para um país estrangeiro, de uma cultura diferente, no qual cada passo inicial, desde alugar a casa, instalar o telefone, ligar o gás, tudo é uma verdadeira batalha. Wildson já havia superado todas essas dificuldades quando eu cheguei para visita-lo e trabalhar com Phil Scott, com quem eu mantinha sólida amizade desde os tempos passados em Leeds, quando Phil tinha apenas um contrato e trabalhava no grupo de Rosalind Driver. Agora ele era professor da Universidade de Leeds e começava a receber meus alunos. Nós preparávamos o livro "Meaning Making in Secondary Science Classrooms" e em 2001 passei duas semanas em Leeds para adiantar as coisas desse livro. Eu acompanhava Wildson atentamente e tivemos bons momentos neste período que passamos juntos. Seus filhos ainda eram crianças e eles dividiam com o pai e com Márcia, a esposa de Wildson, a alegria de estar vivendo uma experiência única em suas vidas.

Como tudo mais na vida, os quatro anos que Wildson se dedicou ao doutorado passaram muito rapidamente. Sua tese, intitulada "Aspectos sócio-científicos em aulas de química", era uma análise consistente do que ocorria em sala de aula de professores quando esses implementavam um ensino com base em questões sócio-científicas. A tese enfatizava dois aspetos que seriam centrais na sua carreira: 1) O "Projeto de Ensino de Química e Sociedade"- PEQUIS, nos quais Wildson atuava junto a outros professores, universitários e do ensino médio, para produzir livros de química para este nível de ensino. 2) As questões ligadas à implementação de um ensino de química para formação da cidadania. Os livros derivados do PEQUIS fazem das questões sóciocientíficas um veículo para a educação para a cidadania. Dentre esses livros destacamos "Química e Sociedade", em volume único, que recebeu o Prêmio Jabuti de livro didático do ensino fundamental e médio em 2001, pela Câmara Brasileira do Livro. E o atual "Química Cidadã", em três volumes. Sua tese continha, portanto, os principais aspectos que Wildson iria trabalhar ao longo de sua vida profissional, que começava agora a ter um novo rumo, pois Wildson tornara-se doutor.

Foi como doutor que Wildson exerceu forte liderança acadêmica, tanto na Sociedade Brasileira de Química e quanto na Universidade de Brasília, instituição na qual ingressou em 1993, com professor assistente. Na Sociedade Brasileira de Química foi da Diretoria da Divisão de Ensino por dois mandatos - 1993/1994 e 1995/1996. Foi também um dos Editores do periódico "Química Nova na Escola" de 2007 a 2015, tendo exercido a coordenação da Editoria de 2013 a 2015. Na UnB teve importante papel na constituição dos mestrados profissionais e programas de pós-graduação na área de Ensino de Ciências. Em 2004, ajudou a criar o Curso de Mestrado Profissionalizante em Ensino de Ciências, atuando na área de concentração Ensino de Química, que foi criada junto com a de Ensino de Física. Em 2007, o Programa de Ensino de Ciências da UnB incorporou a área de Ensino de Biologia. Exerceu a coordenação desse programa a partir de 2015. Atuou também no Programa de Pós-graduação em Educação da UnB, onde orientava também doutorandos. Na sua carreira de professor da pós-graduação orientou 15 dissertações de mestrado e 8 teses de doutorado, além de ter supervisionado 2 pós-doutorandos. A sua dedicação à pós-graduação de forma alguma se deu às custas da graduação, exercida com brilhantismo na licenciatura em Química. Neste curso orientou 78 trabalhos de conclusão e 13 alunos de iniciação científica.

Como pesquisador, Wildson publicou 53 artigos científicos, a grande maioria deles Tecnologia e Sociedade); questões sócio-científicas; letramento científico; livro 
didático de química; formação de professores. Entre esses artigos, eu destaco três que ele próprio considerava como dentre os cinco trabalhos mais relevantes de sua carreira, conforme consta no seu currículo Lattes: o já citado "Uma Análise de Pressupostos Teóricos da Abordagem C-T-S (Ciência-Tecnologia-Sociedade) no Contexto da Educação Brasileira", com o qual tive a honra de colaborar; "Educação científica na perspectiva de letramento como prática social: funções, princípios e desafios", publicado em 2007 na Revista Brasileira de Educação; e "Scientific literacy: A Freirean perspective as a radical view of humanistic science education", publicado em 2009 em Science Education. Wildson continuou sua carreira internacional, aberta com o doutorado sanduíche em Leeds, pois publicou também em "Cultural Studies of Science Education" e vários trabalhos completos em congressos internacionais. Foi membro da Comissão Executiva da Associação Ibero-Americana Ciência-TecnologiaSociedade, sociedade que ajudou a fundar em 2010, ao coordenar o Seminário IberoAmericano Ciência-Tecnologia-Sociedade no Ensino das Ciências. Participou também da coordenação de todos encontros dessa Associação, do XV Encontro Nacional de Ensino de Química realizado em Brasília, em 2010, e de dois Encontros Centro-Oeste de Debates em Ensino de Química, os V e XII ECODECs. Publicou ainda 11 capítulos de livros. Entre estes destaco "Políticas e Práticas de Livros Didáticos de Química: o processo de constituição da inovação $X$ redundância nos livros didáticos de química de 1833 a 1987", publicado no livro de 2008, organizado por Maria Inês Pretrucci Rosa e Adriana Vitorino Rossi "Educação Química no Brasil: memórias, políticas e tendência”. Nesse capítulo nós voltamos a colaborar, dessa vez num tema que é comum nas nossas vidas: o livro didático.

Por último, mas com igual importância, vale lembrar que Wildson sempre atuou fortemente estimulado pelo grupo com o qual convivia, constituído pelos professores e colegas do Instituto de Química da UnB, Roberto Ribeiro da Silva, Ricardo Gauche, Gerson de Souza Mól, Joice de Aguiar Baptista, Patrícia Fernandes Lootens Machado e, mais recentemente, Renata Cardoso de Sá Ribeiro Razuck. Esse forte grupo de Brasília saberá fazer com que o trabalho acadêmico de Wildson não seja esquecido. Aos colegas de todo o Brasil que admiravam Wildson resta celebrar a sua vida e seus feitos.

Recebido: 19 dez. 2016

Aprovado: 19 dez. 2016

DOI: 10.3895/actio.v1n1.5239

Como citar: MORTIMER, E. F. Wildson Luiz Pereira dos Santos. ACTIO, Curitiba, v. 1, n. 1, p. 1-3,

jul./dez. 2016. Disponível em: <https://periodicos.utfpr.edu.br/actio>. Acesso em: XXX.

Correspondência:

Eduardo Fleury Mortimer

Rua Kennedy Maro Campos, 50 30840-440 Belo Horizonte, Minas Gerais, Brasil.

Direito autoral: Este artigo está licenciado sob os termos da Licença Creative Commons-Atribuição 4.0

Internacional. 